\title{
Entrevista a Julián Arévalo, Decano de la Facultad de Economía de la Universidad Externado de Colombia
}

\author{
por Francisco Díaz Toledo*
}

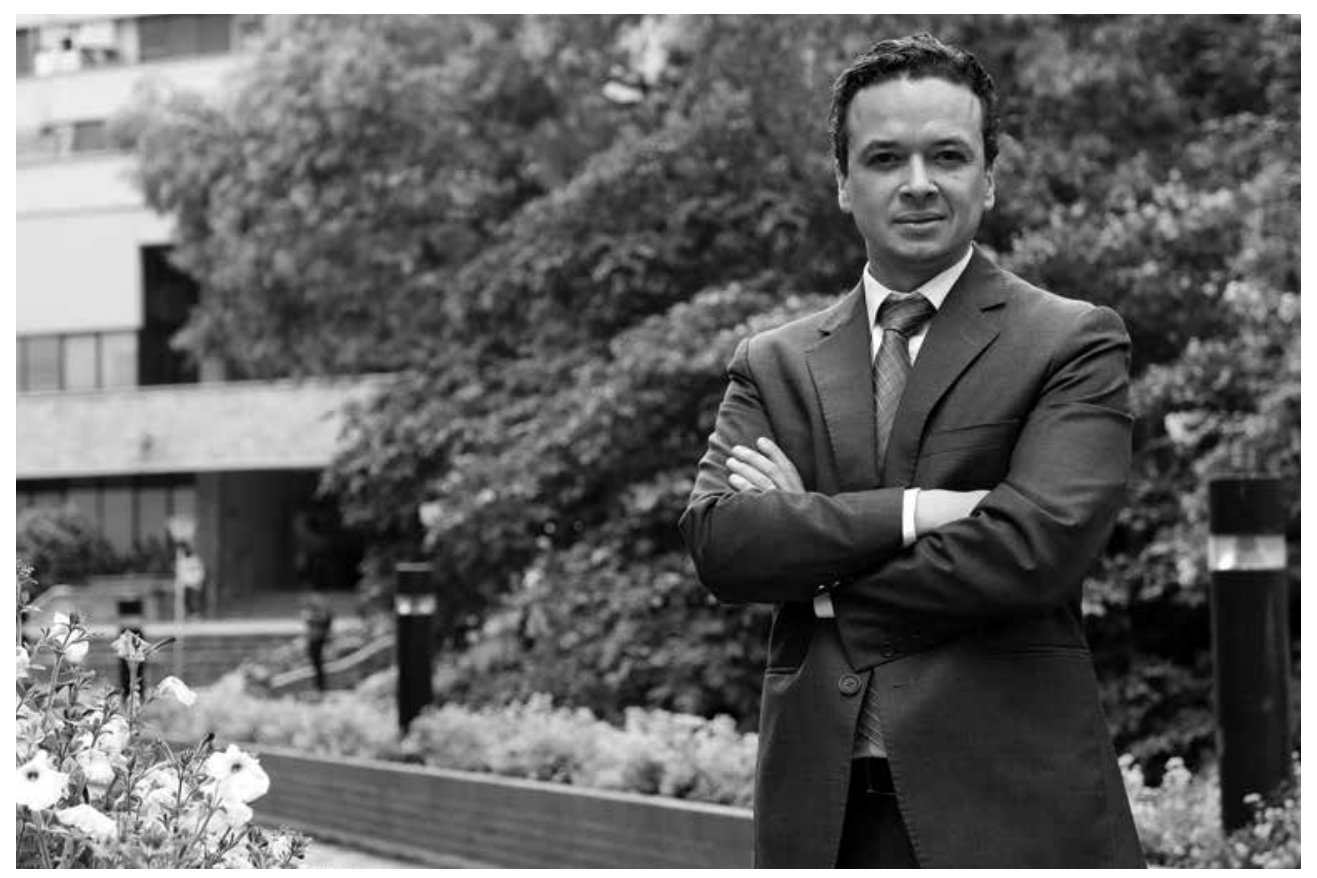

- Bienvenido decano a esta entrevista de la revista Papeles, en su entrega sobre actualidad pedagógica e innovación didáctica. Quisiéramos hablar de los cambios que las facultades de economía se han visto obligadas a asumir en los últimos años, tanto desde las transformaciones en la enseñanza en general y en particular de la economía tras los hechos históricos posteriores a los 80 o los 90. ¿Cómo ha sido este viraje durante estos dos años de repensar la enseñanza de economía como decano?

-Bueno, empecemos por decir que, uno de los retos más importantes que se enfrentan al estar frente a una institución es encontrar un equilibrio adecuado entre todo lo positivo del legado que se recibe y al mismo tiempo introducir algunos cambios necesarios. En particular, como usted bien lo señala, en relación con el contexto cambiante; creo que el reto más importante es ese, y la apuesta de la facultad durante todo este tiempo ha sido muy bien encaminada en esa dirección. El legado que construyó Mauricio Pérez con todo su equipo durante 28 años al frente de la decanatura es

* Profesor de la Universidad Externado. Correo electrónico: francisco.diaz@uexternado.edu.co 
indiscutible, completamente reconocido y al mismo tiempo hay una cantidad de variables que hay que introducir, algunos cambios que hay que implementar para actualizar esa apuesta y ponerse cada vez más en sintonía con esos nuevos desafíos que aparecen en el mundo y en particular en Colombia justamente por los temas que ustedes mencionan.

\section{-Muchas cosas han cambiado: el caso particular de las nuevas tecnologías, el postconflicto.}

-Miremos el caso de las nuevas tecnologías. Hoy tomé una clase, por la que no tuve que pagar edificio, salón, no me tocó pagar matricula, nada de aquello a lo que estamos acostumbrados. Hoy simplemente a través de una aplicación, me conecté con una profesora en otra parte del mundo y tuvimos la clase antes de venir acá. Eso mismo está pasando hoy en muchos temas, como historia, teoría de juegos, macroeconomía, pensamiento económico, ideas políticas, microeconomía, entre muchas otras. Otro dato, hoy hablaba con alguien que me decía que para un estudiante de ciudades diferentes a Bogotá, venir a tomar una de nuestras maestrías o especializaciones, le representa mucho dinero, y sabemos que hay muchas plataformas, muy sofisticadas donde podemos subir contenidos, tener mecanismos interactivos, conectar varias personas simultáneamente, entre otros. En un proyecto del que hago parte, hay miembros de por lo menos 8 países diferentes, y en cada reunión que hacemos mensualmente hay al menos 15 personas conectadas simultáneamente desde Zimbabue, Nigeria, España, Reino Unido, Estados Unidos, Colombia, Venezuela, México, teniendo discusiones muy organizadas. La educación universitaria enfrenta ese desafío; eso es algo que hay que acoger bien. No se trata de ir a prohibir esas nuevas tecnologías como se está haciendo actualmente en otros frentes, sino que hay que entenderlo, y hay que entender que muchos de nuestros estudiantes crecieron viendo eso. Para muchos de nosotros hubo un antes y un después con la llegada del Internet, y nos acordamos la primera vez que tuvimos Internet o que escuchamos hablar de Internet; pero para nuestros estudiantes no; nuestros estudiantes nacieron y seguramente sus papás tomaron una foto con el celular, entonces, si estamos en esa dinámica, sería incorrecto que nos aferremos $100 \%$ a los métodos utilizados antes. El reto es encontrar un balance correcto. ¿Vamos a dejar la universidad, y todas las clases van a ser por Internet y le mandamos unas pruebas por WhatsApp? No se trata de llegar a ese extremo, pero tampoco podemos quedar el $100 \%$ de las clases con el profesor, con la tiza y el tablero, hay que llegar a un buen equilibrio entre las dos cosas donde se pueda virtualizar algunos contenidos y se pueda continuar con ese contacto y aproximación, tan cerrada de los profesores con los estudiantes.

En el caso colombiano, para conectar con otra pregunta, también hay una situación muy especial asociada al final de la guerra que es las diferentes realidades del territorio. Hace algunos días hablaba con alguien que ya había olvidado que hace unos años, medio país no era como lo conocemos actualmente, organizado por departamentos; eran intendencias y comisarias, con el entendido de que eso era otra cosa y había otra realidad que no nos importaba tanto como la de Antioquia, Cundinamarca o Atlántico. Hoy tenemos la conciencia de que si el Estado no hace unas intervenciones claras en esos territorios, pues los ciclos de violencia afectados por esta historia colombiana en sus 200 años de vida republicana van a continuar. Hoy nos corresponde contribuir desde la universidad a todo este proceso de cambio, no podemos seguir pensando un modelo de educación elitista centrado en las principales ciudades que desconoce las heterogeneidades regionales. Hay regiones donde el Estado no ha estado presente, sino que la autoridad ha sido ejercida por grupos armados ilegales. Entonces, si no nos sintonizamos con todas esas realidades, y todas las otras realidades 
Yo creo que instituciones, como es

el caso de las universidades, se ven fortalecidas en tanto todos los grupos

de edad tengan representación, es

decir, que sea más o menos un reflejo de la sociedad.

asociadas al desarrollo tecnológico, pues cada vez el rol de las universidades va a ser menor. Por el contrario, si entendemos mejor esa realidad y nos conectamos con lo que está pasando el rol de educador se hace muy vigente, muy apreciado y muy respetado. Yo le tengo mucho miedo a esa caricatura de Sócrates, en Las nubes de Aristófanes, y le tengo miedo en la medida en que seamos esa caricatura, o si somos realmente el docente que está sintonizando con los problemas de su sociedad, que está sintonizado por las discusiones pertinentes, y no que está como esa caricatura esta allá en las nubes, especulando acerca de lo divino, no de lo humano, con una desconexión completa de los problemas en los que su sociedad está inmersa.

$-i$ Cómo ve usted una nueva enseñanza de la economía para enfrentar la actualidad de la realidad colombiana, en particular, desde el estamento de los antiguos profesores, sus valores y pedagogías, frente a una juventud educada desde el colegio con nuevas técnicas y nuevas perspectivas ideológicas?

-Yo creo que instituciones, como es el caso de las universidades, se ven fortalecidas en tanto todos los grupos de edad tengan representación, es decir, que sea más o menos un reflejo de la sociedad. Primero, los mayores, pues es indiscutible que la gente mayor acumula una experiencia, un conocimiento, una sabiduría que le permite dar discusiones y dar luces sobre diferentes problemas. Pero el joven de 20 años, de los 20 a los 30 aproximadamente tiene unas ganas, unos sueños, una capacidad de trabajo que difícilmente cualquier otra persona tenga; finalmente, está ese grupo intermedio, más o menos entre los 35 y 50 años que son quienes ya culminaron sus estudios, y empiezan sus agendas de trabajo y de investigación personal.. No hay un punto exacto, pero alrededor de esos años ya hay una persona que adquiere un cuerpo de conocimiento suficientemente bueno, tiene ciertas destrezas, ha adquirido bastante bien su objeto de estudio de trabajo y una agenda, tiene más sabiduría que el más joven seguramente, menos que el más viejo, más capacidad que el más viejo y tal vez menos que el más joven $\mathrm{Si}$ se descuida alguno de esos frentes pues no se puede renovar institucionalmente la universidad a sí misma, sino que es dependiente únicamente de cierto grupo de personas que va envejeciendo y no hay un apoyo en la parte de atrás del ciclo generacional

-En esta universidad se está debatiendo mucho sobre el tema de la neurociencia aplicada al derecho y a las ciencias sociales en general. Usted se ubica tal vez en lugar privilegiado desde el punto de vista generacional para opinar sobre esta complejidad actual, pues ha sido educado por los docentes antiguos esta facultad, pero a su vez, no se distancia mucho de las nuevas generaciones.

-Usted me lleva a una discusión sobre la que estoy pensando en estos días. Hay un artículo muy bonito de Boris Salazar del 2007, en el que hace una reflexión sobre el trabajo de un Premio Nobel de economía, llamado Thomas Schlelling. Thomas Schlelling hizo sus principales contribuciones, por allá en el año 56, muy de la época en la que otros como John Nash también estaba haciendo sus contribuciones, luego del trabajo de Von Neumann y Morgenstern, que son los principios de la teoría de juegos. Dentro de todo este paquete estaba también la apuesta del 
señor Thomas Schlelling, pero por diferentes razones la apuesta metodológica y epistemológica que coge fuerza es la de los otros; esto es, un enfoque muy deductivo, a partir de unas características axiomáticas y unos procedimientos que llevan a ciertas conclusiones, mientras que la aproximación más heurística, más creativa, más imaginativa quedó un poco relegada. Sin embargo, aunque esta apuesta no fue la que se puso de moda durante varias décadas muchos años después, con la llegada de la economía del comportamiento, la economía experimental y disciplinas como la neuroeconomía, pareciera que tardíamente se estaba dando la razón a esta aproximación de Thomas Schlelling; o sea, cómo se involucran estas otras herramientas, otras formas de modelar y de entender comportamientos, que son mucho más acordes a las que estamos viendo hoy.

Pareciera que hace más de 70 años no estábamos preparados todavía para entender estas otras aproximaciones, en las que con modelos muy sencillos se puede llegar a conclusiones importantes como segregación, y cómo ciertos microcomportamientos generan macros resultados inesperados en muchos casos. Entonces me parece que hoy, incluso gente que muy inclinada hacia trabajos de microeconomía, econometría, macroeconomía, empiezan a valorar más estas aproximaciones y no solo los enfoques que caracterizaron estas disciplinas durante tanto años.

- Tras las renovaciones que se ha dado ante su llegada a la decanatura se han dicho muchos comentarios sobre los nuevos enfoques y orientaciones frente al legado recibido y las expectativas históricas de la comunidad académica. Se habla en pasillo de una nueva ruta marcada por la microeconomía; no obstante, le hemos escuchado en este lapso como los énfasis de la facultad van más allá, dialogan con la macroeconomía, la econometría, incluso con la tradición del enfoque institucionalista.
-Bueno me alegro que me cuente esto porque la primera parte no me parece precisa. El proyecto institucional no se cierra ni se contempla cerrarse ni en la más remota posibilidad. Mientras yo esté al frente a esta facultad no es posible que eso ocurra. Y justamente estoy diciendo que el reto fundamental de una institución es preservar lo bueno y hacer los ajustes, y si usted me dijera qué es lo mejor que usted recibió, lo mejor es la visión de la economía institucional. Soy muy enfático en esto. De hecho, en el trabajo que se está haciendo en la revista de Economía Institucional, lo considero una apuesta única e innovadora, contestataria frente a mucha formas de hacer economía, y es un legado que quisiera preservar, entre otras por los gigantes que lo construyeron como es el caso de Jesús Antonio Bejarano, a quien tanto admiro. La facultad necesita cada vez más fortalecerse en otros aspectos que es donde me parece que tenemos un pequeño vacío que llenar. Me refiero, como en cualquier facultad de economía del mundo, a un esfuerzo por un balance adecuado entre la macroeconomía, la microeconomía y la econometría. Es clave seguir trabajando en esas áreas.

- Las universidades enfrentan el reto de actualizar sus programas sujetos dar respuesta a los cambios exigidos de las empresas y desde los nuevo paradigmas científicos y laborales; esto lleva constantemente a la toma de decisiones complejas de

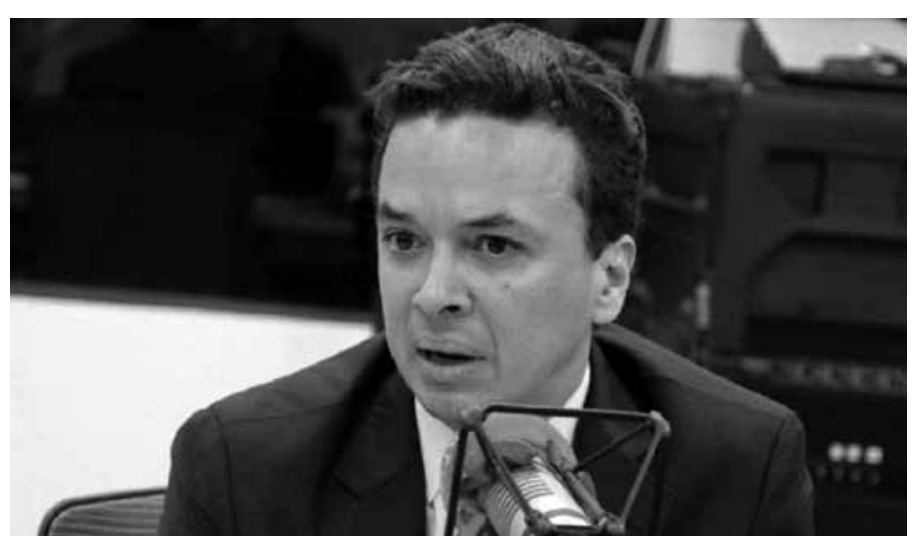




\section{diseño curricular. ¿Cómo ha sido este reto durante su decanatura?}

-Bueno, vamos por partes, entonces, por un lado, aunque la entrevista es para mí, yo quisiera responder que esto no es un proyecto personal, es un proyecto colectivo. Hay muchas definiciones en la línea en que estamos trabajando, temas como los que se mencionaron en la pregunta anterior, como si es economía institucional o de comportamiento. Pero no se trata de si le gusta o no a la persona, sino a los intereses de los colectivos. La economía institucional ha sido una construcción colectiva por muchos años. Las clases no pueden ser lo que le gustan a dos personas, sino lo que surge en un ambiente plural, librepensador, como es el que caracteriza al Externado. Uno de mis mejores profesores, Juan Ricardo Ortega me marcó en una de sus clases con una frase que decía que en cualquiera actividad profesional no importa cuál sea el trabajo, sea panadero, venda celulares, médico, hay que hacer la tarea y está mal no hacerla. En la educación la situación es mucho más grave porque usted está jugando con los sueños de la gente, el tiempo perdido es difícilmente recuperable, son cuatro años de la vida de los estudiantes que se pierden si no se hace un buen trabajo; lo que a usted no le enseñaron en ese curso difícilmente se puede corregir. Yo me pongo en los zapatos de los padres de familia, y uno sabe cuánto vale la educación del hijo, cuánto vale no solo en plata si no en sacrificios: levantarse y darle el desayuno, llevarlo al bus, pagar la matrícula y todo lo demás; es un sacrificio personal y familiar, es un acto de fe, como para que la institución no cumpla con lo que se debe hacer.

Los padres y los muchachos mismos tienen una gran expectativa de ganarse la vida, entonces necesitamos pensar en formar personas académicamente y al mismo tiempo responder a las necesidades de la sociedad respecto a los profesionales que se están demandado.

Se trata de complementar herramientas como hace, por ejemplo, el profesor Enrique Ferrer en la clase de Ideas Políticas. Es maravilloso cuando uno tiene que salir de su rol (los estudiantes deben asumir roles como lavar los baños o pedir limosna), o como conocer la calidad de vida en la ciudad de Bogotá en caminatas, una cantidad de actividades más allá de la academia tradicional, esto también es ser ciudadano y me parece que es muy importante. No reducimos la academia a una fábrica de profesionales, sino a la formación de economistas con una visión integral, y esto es lo que hace la diferencia cuando los estudiantes deciden economía y no derecho o economía pero no a igual administración. 